\title{
Taxonomy, the Cinderella of science, hidden by its evolutionary stepsister
}

\author{
JOSÉ M. PADIAL \& IGNACIO DE LA RIVA \\ Department of Biodiversity and Evolutionary Biology, Museo Nacional de Ciencias Naturales, CSIC; C/José Gutiérrez Abascal, 2, \\ 28006, Madrid, Spain.E-mail: padial@mncn.csic.es, iriva@mncn.csic.es
}

While taxonomy is being glorified during the Linnaean 300th anniversary (Anonymous 2007; Hopper 2007), we have observed a dangerous trend in phylogenetics: the placement of taxonomic discoveries in the appendices of science. Studies that aim to address biogeographical or evolutionary hypotheses using phylogenetic analyses have been confronted with the problem of how to proceed with the taxonomic discoveries that emerge during the analysis of the information (e. g. when discovering that a taxon that was thought to be monophyletic is instead paraphyletic). Authors of such studies may be forced by the editorial policy of high impact journals, either to ignore their own taxonomic results or to treat them marginally by including them in on-line appendices (e. g. Wiens et al. 2005; Heinicke et al. 2007). These cases are likely to be more and more common because of the increasing use of phylogenetics without classification purposes (Wheeler 2004; Franz 2005), together with the lack of complete taxonomic knowledge for most organisms (Dubois 2003a). This situation can lead to the production of "phantom taxonomies": those that first appear in online appendices as downloadable documents, in which both the new taxonomy and the authors are difficult to track. This new term bears a strong resemblance to two other: "phantom nomina" as introduced by Vences et al. (1999) and "phantom references" (Dubois 1999). The term "phantom nomina" refers to new nomina "accidentally" published in amateur publications without proper descriptions and vouchers, while "phantom references" point to references that were quoted as "in press" or " in preparation" but were never published.

Phantom taxonomies are not only at risk of being ignored but also of being rejected by the International Commission of Zoological Nomenclature (for similar arguments related to "nomina nuda" see Dubois et al. [2001]). For example, the International Code of Zoological Nomenclature (Anonymous, 1999) states: "it [work] must be issued for the purpose of providing a public and permanent scientific record" (article 8.1.1); "For a work produced after 1999 by a method other than printing on paper to be accepted as published within the meaning of the Code, it must contain a statement that copies (in the form in which it is published) have been deposited in at least 5 major publicly accessible libraries which are identified by name in the work itself" (article 8.6); "Authors and publishers are strongly urged to ensure that a new scientific name or nomenclatural act is first published in a work printed on paper" (recommendation 8B).

The placement of new taxonomic results in online supplementary information does not only work against the Code but also does not contribute to the support of taxonomy as a science. The descriptions of new taxa and proposals of new names are taxonomic hypotheses that cannot be relegated to "un-authored" online appendices as downloadable raw textdocuments. This practice equates taxonomic results to the lengthy descriptions of standardized methodologies. Taxonomic information deserves to be treated as relevant information. Taxonomic hypotheses should be fully accessible to everybody in the long term, and this can only be achieved when they are included in the main body of original articles, be electronic or printed format. The latter has allowed most taxonomic hypotheses to endure for centuries in their original works, catalogued in libraries of natural history museums and universities around the world. However, access to electronic files in the long term is not guaranteed for the moment (Dubois 2003b). Even if taxonomic works were to be only published electronically, as has already been envisioned (Wheeler et al. 2004; Hopper 2007), authorship and access in the long term should be ensured. Taxonomic results need to be both accessible and enduring.

A possible criticism of our view relates to the longstanding problem of accessibility to the many taxonomic descriptions and nomenclatural changes published in obscure journals with almost no access or peer-review ("gray literature"). Of course, we strongly reject this practice. Nowadays, there are many taxonomic journals that publish both online and printed copies. Even more general scientific journals occasionally publish full descriptions of new taxa (e. g. Biju \& Bussuyt 2003; Min et al. 2005). Nevertheless, taxonomy should not be dragged down by the space restrictions imposed upon it by the steadily increasing rate of publication in other disciplines. Unreliable taxonomic information stemming from the need for rapid publication is equally unacceptable (Wheeler et al. 2004) given that, in taxonomy, unlike other disciplines, poor science cannot be ignored (Giribet \& Wheeler 2007). 
For all these reasons, taxonomists should discourage authors, editors of journals, and referees from reporting original descriptions, definitions of new taxa, and proposals for taxonomic changes in on-line supplementary information. If taxonomies cannot be included in the main body of phylogenetic or biogeography-oriented papers, they should be published elsewhere as full peer-reviewed articles.

Acknowledgments. To Paul Bloor, for his help with the English and enthusiastic discussion. To Alan Dubois, Quentin D. Wheeler, and three anonymous referees for their constructive criticisms.

\section{References}

Anonymous [International Commission on Zoological Nomenclature] (1999) International Code of Zoological Nomenclature. Fourth edition. International Trust for Zoological Nomenclature, London, 335 pp.

Anonymous (2007) The legacy of Linnaeus. Nature, 446, 231-232.

Biju S.D. \& Bossuyt, F. (2003) New frog family from India reveals an ancient biogeographical link with the Seychelles. Nature, 425, 711-714.

Dubois, A. (1999) Miscellanea nomenclatorica batrachologica. 19. Notes on the nomenclature of Ranidae and related groups. Alytes, 17, 81-100.

Dubois, A. (2003a) The relationships between taxonomy and conservation biology in the century of extinctions. Comptes Rendus Biologies, 326, S9-S21.

Dubois, A. (2003b) Should internet sites be mentioned in the bibliographies of scientific publications? Alytes, 21, 1-2.

Dubois, A., Ohler, A. \& Biju, S.D. (2001) A new genus and species of Ranidae (Amphibia, Anura) from south-western India. Alytes, 19, 53-79.

Franz, N.M. (2005) On the lack of good scientific reasons for the growing phylogeny/classification gap. Cladistics, 21, 495-500.

Giribet, G. \& Wheeler, W.C. (2007) The case for sensitivity: a response to Grant and Kluge. Cladistics, $23,1-3$.

Heinicke, M.P., Duellman, W.E. \& Hedges, S.B. (2007) Major Caribbean and Central American frog faunas originated by ancient oceanic dispersal. Proceedings of the National Academy of Sciences USA, 104, 10092-10097.

Hopper, S.D. (2007) New life for systematics. Science, 316, 1097.

Min, M.S., Yang, S.Y., Bonnet, R.M., Vieites, D.R., Brandon, R.A. \& Wake, D.B. (2005) Discovery of the first Asian plethodontid salamander. Nature, 435, 87-90.

Vences, M., Glaw, F. \& Böhme, W. (1999) A review of the genus Mantella (Anura, Ranidae, Mantellinae): taxonomy, distribution and conservation of Malagasy poison frogs. Alytes, 17, 3-72.

Wheeler, Q.D. (2004) Taxonomic triage and the poverty of phylogeny. Philosophical Transactions of the Royal Society of London B, 359, 571-583.

Wheeler, Q.D., Raven, P.H. \& Wilson, E. O. (2004) Taxonomy: Impediment or expedient? Science, $303,285$.

Wiens, J.J., Fetzner, J.W., Parkinson, C.L. \& Reeder, T.W. (2005) Hylid frog phylogeny and sampling strategies for speciose clades. Systematic Biology, 54, 719-748. 